\title{
Genome-Wide DNA Methylation Dynamics During Drought Responsiveness in Tibetan Hulless Barley
}

\section{Dunzhu Jabu}

Tibet Academy of Agricultural and Animal Husbandry Sciences

\section{Zhaiming Yu}

Tibet Academy of Agricultural and Animal Husbandry Sciences

\section{Qijun Xu}

Tibet Academy of Agricultural and Animal Husbandry Sciences

\section{Haizhen Yang}

Tibet Academy of Agricultural and Animal Husbandry Sciences

\section{Wang Mu}

Tibet Academy of Agricultural and Animal Husbandry Sciences

Basang Yuzhen ( $\square$ alipulan@yeah.net )

Tibet Academy of Agricultural and Animal Husbandry Sciences https://orcid.org/0000-0002-1951-7128

\section{Research Article}

Keywords: Hulless Barley, Drought stress, DNA methylation, Transcription factors

Posted Date: October 18th, 2021

DOI: https://doi.org/10.21203/rs.3.rs-938198/v1

License: (c) (1) This work is licensed under a Creative Commons Attribution 4.0 International License. Read Full License 


\section{Abstract}

Differences in drought stress tolerance within diverse grass genotypes have been attributed to epigenetic modifications. DNA methylation is an important epigenetic alteration regulating responses to drought-stress. However, its effects on drought-tolerance are poorly understood in Tibetan hulless barley. Here, bisulfite sequencing was conducted to profile the DNA methylation patterns of drought-tolerant variety XL and drought-sensitive one DQ under drought and control conditions. A total of 5843 million reads were generated. We found the significant genome-wide changes in $\mathrm{CHH}$ methylation rates between XL and DQ, while CG or CHG methylation rates did not. Besides that, the two contrasting varieties do reveal distinct responses to drought-stress in differentially methylated region (DMR) numbers and antioxidant activities. Genes in drought-tolerant varieties XL are rapidly and significantly methylated to alleviate the drought stress. DMR related genes in XL might involve in defense response and response to stimuli, which are confirmed by gene ontology analysis. Then, we focused on 1003 transcription factors and identified 15 specific DMR related transcription factors exhibiting specific methylation changes under drought stimuli. Finally, we identified three DMR related TFs (HVUL6H08680.2, HVUL4 h39100.2, and HVUL2H41931.2) where Arabidopsis homologues involve in responses to drought conditions. Altogether, DNA methylation regulate responsiveness to environmental stimuli, which could be mediated by methylation of transcription factors in hulless barely.

\section{Introduction}

Hulless barley (Hordeum vuglare L. var. nudum Hook. f.), also called naked barley, is an important cereal crop in Tibet Plateau(Xu et al., 2016). It has been served as a healthy food for human consumption and animal feed for over thousands of years. Owing to high altitudes, the naked barley is cultivated in harsh environment such as valleys and higher land on Tibet(Liang et al., 2017). It is also affected by drought and low temperature in March every year when the weather is quite cold and dry(J. B. Du et al., 2011). In order to mitigate adversities such as drought, salinity, and low temperature, various strategies have been evolved in hulless barley( $\mathrm{H}$. Li, Guo, Lan, Zhou, \& Wei, 2014).

It is well-known that drought is the most serious environmental stress that affect crop growth and yield by causing a wide range of physiological and biochemical responses(Flowers, 1989; Iqbal, Murtaza, Saqib, \& Ahmad, 2015). The influences of drought on the crop varies between varieties and developmental stages. Many genes responsible for drought tolerance have been reported for decades(Lenka, Katiyar, Chinnusamy, \& Bansal, 2015; Moa, Liua, Lina, Xub, \& Xianga, 2005). For example, the transcription factor AtHB13 has been reported to act as a positive regulator of drought tolerance in Arabidopsis. Genetically, drought tolerance is extremely complex trait involving in several genetic pathways such as polygenic control and complex morpho-physiological mechanisms(Xuekun Zhang et al., 2014). At the molecular level, drought stress could induce genome-wide changes in gene expression via epigenetic mechanisms like histone modification and DNA methylation in plants(Wang et al., 2016; Zong, Zhong, You, \& Xiong, 2013). For example, the mutant allele (met1) DNA methyltransferase 1 locus could remove methylation at several genomic regions leading to specific expression of 31 stress response-related genes in tobacco(Ku, Lim, \& Park, 2006; Zubko, Gentry, Kunova, \& Meyer, 2012).

DNA methylation, an epigenetic modification, play crucial roles in plant growth and development as well as responses to various abiotic stresses(Arthur et al., 2018; Uthup, Ravindran, Bini, \& Thakurdas, 2011). Actually, DNA methylation exists in all eukaryotes, and it frequently occurs at the 5 -position of cytosine $(5 \mathrm{mC})$ (Kasai \& Kawai, 2009). Under normal conditions, the proportion of methylcytosine in plants is $20-30 \%$ in plants, which usually occurs in three nucleotide sequences: $\mathrm{CG}, \mathrm{CHG}$ and $\mathrm{CHH}$ (H indicates $\mathrm{C}$, T or A)(Serre, Lee, \& Ting, 2009). CG methylation is produced by the conserved DNA methyltransferase METHYLTRANSFERASE1 (MET1)(Zubko et al., 2012); CHG methylation is modified by the plant specific DNA methyltransferase CHROMOMETHYLASE3 (CMT3)(J. Du et al., 2012); and the de novo $\mathrm{CHH}$ is methylated by 24-nucleotide small interfering RNA dependent DNA methylation (RdDM) pathway(Ma et al., 2015). Interestingly, methylation levels contribute greatly to the process of adaptation to stress in plants. The hyper or hypo methylation changes in the hybrids could be an indicator of the expression levels of stress related gene under drought, when compared to their parents(Boyko et al., 2010; Hai \& Zhang, 2009). This indicates the methylcytosine and its reversibility may regulate transgenerational response to stresses. An increasing number of studies revealed the transposon-rich heterochromatic regions show heavily methylation(Melamed-Bessudo \& Levy, 2012). Over one-third of expressed genes are methylated within transcribed regions, while only $5 \%$ genes within their promoter regions in Arabidopsis(Xiaoyu Zhang et al., 2006). Thus, DNA methylation within genes is a common feature of eukaryotic genomes. Intriguingly, methylation of transcribed regions does not usually result in gene silencing(Xiaoyu Zhang et al., 2006). It seems to primarily occur at CG sites and appears to show 
moderate correlation between the level of gene-body methylation and gene expression(Su, Wang, Xing, Liu, \& Yong, 2014). DNA methylation shows the deposition of certain chromatin marks such as differentially modified histones because of the tight link between DNA methylation and histone modifications(Fuks, 2005). For instance, there is a relationship between the reduce in DNA methylation levels and the changes in level of H3K4me and H3K9me modifications in DECREASE IN DNA METHYLATION1 (DDM1) mutant, which maintain cytosine DNA methylation within the heterochromatic locus regions(Sasaki, Kobayashi, Saze, \& Kakutani, 2012; Zhou et al., 2013).

It is the first time that the epigenetic responses to drought between two contrasting varieties were revealed via bisulfite sequencing and RNA sequencing in Tibetan hulless barely. Here, we explored how DNA methylation is involved in drought responsiveness. Changes in the level of DNA methylation affect plant resistance to drought, especially the methylation changes of several transcription factor genes. Therefore, epigenetic changes in genome could be considered as an important regulatory mechanism for plants to adapt to drought and possibly other environmental stresses.

\section{Materials And Methods Plant materials and treatments}

The Tibetan hulless barley ( $\mathrm{H}$. vulgare subsp. vulgare) varieties $\mathrm{XL}$ and $\mathrm{DQ}$ were used. The $\mathrm{XL}$ variety is highly resistant to drought stress, while the $D Q$ is sensitive. Healthy seeds were sterilized by soaking in $2 \% \mathrm{H}_{2} \mathrm{O}_{2}$ for 40 min, and rinsed in sterile water. Finally, seeds were germinated on moistened filter paper at $16-18^{\circ} \mathrm{C}$ with 18 -h light $/ 10-\mathrm{h}$ dark photoperiod and a relative humidity of $80 \%$ in a growth chamber. Artificial water stress was induced with $21 \%$ polyethylene glycol (PEG) 6000 solutions to achieve an osmotic potential. The roots and leaves were harvested from 10-day-old seedlings from two genotypes under normal and drought conditions at $0 \mathrm{~h}, 4 \mathrm{~h}$, and $48 \mathrm{~h}$, respectively; two plants from each pot were considered as biological replicates. All these tissue samples mentioned above were fast frozen in nitrogen and stored at $-80{ }^{\circ} \mathrm{C}$ immediately.

\section{Determination of the MDA content}

The level of lipid peroxidation in plant tissues was measured by determination of MDA, which was measured using the thiobarbituric acid (TBA) method(Schmedes \& H?Imer, 1989). About $0.3 \mathrm{~g}$ leaf sample of hulless barley seedling was homogenized with a mortar and pestle in $5 \mathrm{~mL} 0.1 \%$ Trichloro acetic acid (TCA), then the homogenate was centrifuged at $10,000 \mathrm{~g}$ for $15 \mathrm{~min}$. About $5 \mathrm{ml}$ of $20 \%$ TCA containing $0.5 \%$ TBA was added to $1 \mathrm{ml}$ supernatant aliquot. The mixture was heated at $95^{\circ} \mathrm{C}$ for 10 min, cooled immediately, and centrifuged at $10,000 \mathrm{~g}$ for $15 \mathrm{~min}$. The reaction products of MDA and TBA show highest absorbance at $532 \mathrm{~nm}$. Finally, MDA concentration was calculated using the following method.

\section{Determination of Peroxidase (POD) and Catalase (CAT) Activity}

To analyze the activities of plant antioxidant enzyme (POD,CAT), about $0.5 \mathrm{~g}$ frozen leaf samples were homogenized with a mortar and pestle in ice bath at a 1:10 ratio with $100 \mathrm{mM}$ phosphate buffer saline containing $1 \mathrm{mM}$ EDTA and 1\% polyvinylpyrolidone (PVP). The crude homogenates were centrifuged at $10,000 \mathrm{~g}$ for $15 \mathrm{~min}$ at $4{ }^{\circ} \mathrm{C}$. The supernatant was used to determine the POD and CAT activities.

POD activity was measured by spectrophotometer following change of absorption at $420 \mathrm{~nm}$ due to guaiacol oxidation(Tamas, Mistrik, \& Zelinova, 2016). Under these conditions, one unit of POD activity was defined as the amount of POD that was require for $50 \%$ inhibition of the enzymatic reaction in $1 \mathrm{ml}$ enzyme extraction of per milligram of protein(Yu, Lv, \& Shi, 2009). CAT activity was measured, which based on the fact that ammonium molybdate could rapidly terminate the $\mathrm{H}_{2} \mathrm{O}_{2}$ degradation reaction catalysed by CAT and generate a yellow complex. This complex is monitored by absorbance at $405 \mathrm{~nm}$ using the spectrophotometer. One unit of CAT activity was defined as 1 mmol $\mathrm{H}_{2} \mathrm{O}_{2}$ decomposed in one milligram of protein per second.

\section{DNA extraction and BS-Seq}

The DNA was isolated using a cetyltrimethylammonium bromide (CTAB) method form hulless barley leaves; the integrity was checked by agarose gel electrophoresis; the concentration was measured via a non-ultraviolet method(Allen, Flores-Vergara, Krasynanski, Kumar, \& Thompson, 2006). Bisulfte treatment, library construction and sequencing were conducted by the company (Igenebook Co. Ltd). Un-methylated lambda DNA was spiked in to determine non-conversion rate, and conversion rate for all libraries 
was higher than 99\%. Finally, paired-end bisulfte-treated sample libraries were constructed and sequenced. In addition, a library was constructed from untreated DNA and sequenced as a control.

\section{BS-seq data analysis}

After removing low-quality reads, clean data were mapped to reference genome using BSMAP software (version: 2.9) which permits $8 \%$ mismatch per read(Xi \& $\mathrm{Li}, 2009)$. Then, methylation levels were calculated based on the cytosine percentage in a given position by a custom Perl script(Macisaac, Bogutz, Morrissy, \& Lefebvre, 2012). The methylation profiles for flanking $2 \mathrm{~kb}$ regions and the CDS were plotted based on average methylation levels for each 100bp interval. Differentially methylation regions (DMRs) were identified using the tDMR package between three tissue samples with the following criteria: (a) at least five methylated cytosine sites in at least one sample; (b) coverage by more than ten reads; (c) a distance between adjacent methylated sites was less than or equal to $200 \mathrm{bp}$; (d) a length of the region was between 40bp and 10,000bp; (e) a difference in methylation levels was at least two with a test value of $p \leqq 0.05$ (Song et al., 2009).

\section{Results}

\section{Physiological and biochemical differences between two contrasting hulless barley varieties}

Reactive oxygen species (ROS) excessively accumulates in plant tissues exposed to drought stress. To analyze physiological and biochemical changes in drought-tolerant variety $(\mathrm{XL})$ and drought-sensitive one (DQ), leaves were harvested to investigate changes of Malondialdehyde (MDA) concentration and enzymatic activity (Catalase, Peroxidase) after exposure to drought for $48 \mathrm{~h}$. Firstly, concentration of MDA was tested in leaves, because MDA could serve as the biomarker for cellular and oxidative damage. MDA concentration significantly decreased in $X L$ under drought stress conditions in leaves, while it enhanced sharply in $D Q$ (Fig. 1A). The extremely slight cellular damage is observed in XL, which are consistent with the previous results(Q. Li et al., 2015). This suggests XL is more tolerable to drought stress when compared with the $D Q$ variety.

Then, peroxidase (POD) activities and catalase (CAT) activities are analyzed in Tibetan hulless barley leaves. POD activities obviously reduced in XL under drought conditions, while it rose in DQ (Fig. 1B). On the contrary, activity of catalase (CAT) showed contrasting trends. CAT activities shew 1.64 folds rise in $\mathrm{XL}$ when compared to normal conditions, whereas it decreased by around $50 \%$ in DQ (Fig. 1C). Therefore, CTA might involve in improving drought tolerance in the drought-tolerant variety DQ, but POD activities might negatively correlate to the drought-tolerant genotypes in hulless barley. Also, we detected the MDA, POD, and CAT contents in roots to testify the change patterns in different plant tissues. A similar dynamical changes was observed in XL and DQ varieties, suggesting that the plant organs might exhibit identical responses to drought conditions.

\section{DNA methylomes of Tibetan hulless barley under drought conditions}

In order to reveal the dynamics of genome-wide DNA methylation in contrasting Tibetan hulless barley varieties, we sequenced DNA methylomes of the hulless barley exposed to drought stresses for $0 \mathrm{~h}, 4 \mathrm{~h}$ and $72 \mathrm{~h}$ via bisulfite sequencing, respectively. Two replicates were conducted to assess biological and experimental reproducibility in DNA methylome analysis. Finally, a total of 5843 million 150bp paired-end reads were generated from sodium bisulfte treated DNA with $99 \%$ bisulfte conversion rate for each library. On an average, about 583 million $150 \mathrm{bp}$ sequencing reads was aligned to hulless barely genome for each sample with 25fold coverage of the genome. An average of $52 \%$ clean read pairs were aligned to genome for each library (Table S1).

Genome-wide cytosine methylation at CG, CHG and CHH sequences was determined in all hulless barley samples. An average of $91.71 \%$ CG and $67.36 \%$ CHG was methylated in these samples, both of which shew higher methylation levels. In contrast, only $3.14 \%$ $\mathrm{CHH}$ was methylated, i.e. the lowest level of methylation (Table S2, Fig. 2A). In addition, we determined DNA methylation patterns in $2 \mathrm{~kb}$ upstream of the transcription start site (TSS), gene body, and $2 \mathrm{~kb}$ downstream of the transcription termination site (TTS). CG and CHG were methylated at gene bodies and their flanking regions with an obvious drop around TSS and TTS sites, which are consistent with the previous findings(Q. Li et al., 2015). In contrast, $\mathrm{CHH}$ methylation levels in both flanking regions were higher than that in gene bodies (Fig. S1).

We further determined and analyzed the $\mathrm{CG}, \mathrm{CHG}, \mathrm{CHH}$ methylation rates in these samples. The results revealed there were no signifcant genome-wide changes in CG or CHG methylation rates between the drought-tolerant variety $(\mathrm{XL})$ and the drought-sensitive

Page $4 / 15$ 
one (DQ) at $4 \mathrm{~h}$ and $48 \mathrm{~h}$, respectively (Fig. 2B). Nevertheless, $\mathrm{CHH}$ methylation rates decreased by $6 \%$ from $4 \mathrm{~h}$ to $48 \mathrm{~h}$ in the DQ variety, whereas it significantly increased by $48 \%$ in $\mathrm{XL}$ (Fig. $2 \mathrm{C}$ ). This suggests $\mathrm{CHH}$ contents methylation contribute to the drought tolerance in Tibetan hulless barley, because $\mathrm{CHH}$ is specifically methylated by 24-nucleotide small interfering RNA dependent DNA methylation (RdDM) pathway.

\section{Analysis of differentially methylation regions within same hulless barley varieties between normal and drought conditions}

Differentially methylation regions (upstream of TSS, gene body, and downstream of TTS) were selected and identified, when we compared methylation regions within the same variety between drought and normal conditions at different periods. First of all, the CG-type, CHG-type and CHH-type DMR numbers were compared within drought-tolerant genotypes XL or drought-sensitive one DQ, respectively (Table 1). The results exhibited significant differences between XL and DQ. A total of 1840 and 141 DMR were identified in $\mathrm{XL}$ at $4 \mathrm{~h}$ and $48 \mathrm{~h}$ when compared between the two conditions, respectively. But, there were just about $50 \mathrm{DMR}$ both at $4 \mathrm{~h}$ and 48 $\mathrm{h}$ in DQ. The results indicate that genes in drought-tolerant varieties $\mathrm{XL}$ are rapidly and significantly methylated to mitigate the drought stress, especially in $4 \mathrm{~h}$ after exposed to drought conditions. Then, we analyzed the number of CG-type, $\mathrm{CHG}$-type and $\mathrm{CHH}$ type DMR in XL and DQ at 4h. There were 1104 CG-type DMR, 660 CHG-type DMR and 76 CHH-type DMR in XL, but there were only 15 CG-type DMR, 18 CHG-type DMR and 29 CHH-type DMR in DQ. Considering the significant difference of DMR numbers between $\mathrm{XL}$ and $\mathrm{DQ}$, the two contrasting varieties exhibits distinct responses to drought stress by methylating DNA. Thus, the DMR related genes in the three categories in XL might involve in response to drought stimuli. Then, these genes in XL or DQ were further analysed by gene ontology (GO). We found that CG-type related DMR genes in XL were markedly enriched for nucleotide binding, ADP binding, defense response, and response to stimulus (Fig. 3A).

Table 1

Statistics of the number of different methylation regions (DMR) within XL or DQ

\begin{tabular}{|llllll|}
\hline Variety & $\begin{array}{l}\text { Category / } \\
\text { Combination }\end{array}$ & Total DMR & $\begin{array}{l}\text { CG-type } \\
\text { DMR }\end{array}$ & $\begin{array}{l}\text { CHG-type } \\
\text { DMR }\end{array}$ & $\begin{array}{l}\text { CHH-type } \\
\text { DMR }\end{array}$ \\
\hline Drought-tolerant XL & DR_4h_vs_CK_4h & 1840 & 1104 & 660 & 76 \\
\cline { 2 - 6 } & DR_48h_vs_CK_48h & 141 & 55 & 22 & 64 \\
Drought-sensitive DQ & DR_4h_vs_CK_4h & 62 & 15 & 18 & 29 \\
\cline { 2 - 6 } & DR_48h_vs_CK_48h & 50 & 7 & 17 & 26 \\
\hline
\end{tabular}

\section{Comparative differentially methylation regions between two contrasting varieties}

In order to reveal molecular mechanism of drought tolerance, we compared the levels of methylation and gene expression between two contrasting varieties $\mathrm{XL}$ and DQ. Firstly, differentially methylation regions (DMR) were calculated and compared between $\mathrm{XL}$ and DQ under normal and drought conditions at $0 \mathrm{~h}, 4 \mathrm{~h}$ and $48 \mathrm{~h}$, respectively. As shown in Table 2, the number of CG-type DMR slightly increased by $5 \%$ at $4 \mathrm{~h}$ when compared to $0 \mathrm{~h}$ between $\mathrm{XL}$ and DQ under normal conditions. However it sharply increased by $40 \%$ at 4 $\mathrm{h}$ under drought conditions. The similar trends were observed in the number of CHG-type and CHH-type DMR. The changes of DMR number between $\mathrm{XL}$ and $\mathrm{DQ}$ under drought conditions is more obvious than that under normal conditions, suggesting drought stress could induce DNA methylation to response to abiotic stimulus quickly. Interestingly, the number of DMR in CG, CHG, and CHH sequences between two varieties reduced from $4 \mathrm{~h}$ to $48 \mathrm{~h}$ under drought stress, but it increased under normal conditions. The contrasting DMR number changes between normal and drought conditions suggested that DNA methylation might regulate responsiveness to environmental stimuli. Furthermore, we conducted gene ontology (GO) analysis by using these DMR-related genes between XL and DQ exposed to drought stress. We found CG-type DMR-related genes were significantly enriched for cellular response to stimulus, response to stress, nucleotide binding, lyase activity, isomerase activity, hydrolase activity (Fig. 3B). 
Table 2

Statistics of the number of different methylation regions (DMR) between two contrasting varieties $\mathrm{XL}$ and DQ

\begin{tabular}{|lllll|}
\hline Sample & & CG-type DMR & CHG-type DMR & CHH-type DMR \\
\hline Normal & XL_CK_0h_vs_DQ_CK_0h & 909 & 494 & 42 \\
\cline { 2 - 5 } condotions & XL_CK_4h_vs_DQ_CK_4h & 958 & 542 & 115 \\
\cline { 2 - 5 } & XL_CK_48h_vs_DQ_CK_48h & 1354 & 858 & 109 \\
\multirow{2}{*}{$\begin{array}{l}\text { Drought } \\
\text { conditions }\end{array}$} & XL_DR_4h_vs_DQ_DR_4h & 1276 & 812 & 181 \\
\cline { 2 - 5 } & XL_DR_48h_vs_DQ_DR_48h & 771 & 340 & 144 \\
\cline { 2 - 5 } & &
\end{tabular}

Then, CG-type, CHG-type and CHH-type related genes were identified and calculated between XL and DQ both in drought and normal conditions. As shown in Table S3, a number of 284 CG-type genes, 205 CHG-type genes and 51 CHH-type genes between two genotypes were identified at $4 \mathrm{~h}$, while $152 \mathrm{CG}$-type genes, $97 \mathrm{CHG}$-type genes and $35 \mathrm{CHH}$-type genes were identified at $48 \mathrm{~h}$. The results suggest that Tibetan hulless barley could quickly activate more genes to alleviate drought damage. Besides, we performed cluster analysis of these DMR related genes, of which more than $50 \%$ were transcribed. The results exhibit markedly opposite expression profiles of CG-type, CHG-type and CHH-type related genes between two contrasting varieties at $4 \mathrm{~h}$ and $48 \mathrm{~h}$ (Fig. 4).

\section{Identification of differentially methylation regions related transcription factors in hulless barley exposed to drought stress}

To identify differentially methylation regions related transcription factors (TF) in hulless barley after exposure to drought stress, we compared the bisulfite sequencing profiles of both between two contrasting varieties and within same genotypes under drought conditions and normal conditions at $0 \mathrm{~h}, 4 \mathrm{~h}$, and $48 \mathrm{~h}$, respectively. We mainly focused on the four groups of TF (AP2/ EREB, bZIP, $N A C$ and $M Y B$ ), which could involve in response to abiotic stresses in plants such as Arabidopsis thaliana and rice. A total of 659 TFs were identified according nucleotide sequence analysis of TFs from Tibetan hulless barley, which is homologous to these from rice (Table S4). Of the 659 TFs, 26 unique TFs (11 MYB, 9 NAC, 5 AP2/DREB, and 1 bZIP) appeared to be differentially methylated between different comparative combinations (Table S5). Intriguingly, 46 DMR related TFs were indentified in total, but there were as many as 20 repetitive DMR related TFs among different combinations (Table S6).

To identify DMR related TFs that respond to drought conditions, we compared the DMR related TFs selected from the combinations exposed to drought conditions with these from the combinations exposed to normal conditions. As a result, 15 specific DMR related TFs that specifically exhibit significant methylation changes under drought stimuli were identified, indicating the 15 TFs are induced by drought-stress (Table 3). Among these TFs, we found three hulless barley TFs whose gene homologue from Arabidopsis thaliana mediate responses to drought stresses(Rohit et al., 2016; Sultana, Khurram, Akihiro, Maho, \& Motoaki, 2016). RR12, HVUL6H08680.2 gene homologue from Arabidopsis thaliana, encoding type B cytokinin response regulators negatively regulate plant responses to drought; RR2 that is homologous to HVUL4 h39100.2 exhibits tolerance to drought and salt stresses; CSP41B with homology to HVUL2H41931.2 is modulated by miR399f to mediate plant responses to salt, ABA, and drought. Besides that, 4 specific Arabidopsis TFs also could involve in abiotic and biotic stresses except for drought stress. ANAC102 with homolog to both HVUL7H38638.2 and HVUL3H21712.2 mediates response to low oxygen stress; AtTDR1 with homolog to HVUL 1H37933.2 enhances tolerance to salt stress via activation of ABA synthesis in Arabidopsis; ATMYB71 with homolog to HVUL4 h24905.2 might regulate plant defense via promoter-based integration. Of those remaining 8 specific DMR TFs, their homologous genes in Arabidopsis encode putative proteins with unknown functions. 
Table 3

Drought stress responsive DMR transcription factors

\begin{tabular}{|c|c|c|c|c|c|}
\hline $\begin{array}{l}\text { Hulless } \\
\text { barely_ID }\end{array}$ & Ath_ID & Gene function & Ath_Annotation & Rice_ID & Rice_Annotation \\
\hline HVUL7H38638.2 & AT5G63790.1 & $\begin{array}{l}\text { ANAC102 } \\
\text { appears to } \\
\text { have a role } \\
\text { in mediating } \\
\text { response to } \\
\text { low oxygen } \\
\text { stress } \\
\text { (hypoxia) in } \\
\text { germinating } \\
\text { seedlings. }\end{array}$ & $\begin{array}{l}\text { ANAC102,NAC } \\
\text { domain } \\
\text { containing } \\
\text { protein } 102\end{array}$ & LOC_Os01g66120.1 & $\begin{array}{l}\text { No apical meristem } \\
\text { protein, } \\
\text { putative, expressed }\end{array}$ \\
\hline HVUL6H08680.2 & AT2G25180.1 & $\begin{array}{l}\text { Arabidopsis } \\
\text { type B } \\
\text { cytokinin } \\
\text { response } \\
\text { regulators } \\
\text { ARR1, ARR10, } \\
\text { and ARR12 } \\
\text { negatively } \\
\text { regulate plant } \\
\text { responses to } \\
\text { drought. }\end{array}$ & $\begin{array}{l}\text { RR12, } \\
\text { response } \\
\text { regulator } 12\end{array}$ & LOC_Os02g08500.1 & $\begin{array}{l}\text { two-component response } \\
\text { regulator, } \\
\text { putative, expressed }\end{array}$ \\
\hline HVUL6H52348.2 & $\mathrm{Na}$ & Unknown & Unknown & LOC_Os11g03870.1 & $\begin{array}{l}\text { LTPL31 - Protease } \\
\text { inhibitor/seed storage/ } \\
\text { LTP family protein } \\
\text { precursor }\end{array}$ \\
\hline HVUL4H47728.2 & $\mathrm{Na}$ & Unknown & Unknown & ChrUn.fgenesh.mRNA.49 & expressed protein \\
\hline HVUL4H39100.2 & AT4G16110.1 & $\begin{array}{l}\text { Whereas, RR1, } \\
\text { RR2, RR3, and } \\
\text { RR4 } \\
\text { transformants } \\
\text { exhibited } \\
\text { tolerance to } \\
\text { drought and } \\
\text { salt stresses } \\
\text { but were } \\
\text { found to } \\
\text { be sensitive to } \\
\text { the heat } \\
\text { stress }\end{array}$ & $\begin{array}{l}\text { RR2, } \\
\text { response } \\
\text { regulator } 2\end{array}$ & LOC_Os03g12350.4 & $\begin{array}{l}\text { two-component response } \\
\text { regulator, } \\
\text { putative, expressed }\end{array}$ \\
\hline HVUL1H53471.2 & AT5G05800.1 & Unknown & $\begin{array}{l}\text { Unknown } \\
\text { protein }\end{array}$ & LOC_Os02g53020.1 & $\begin{array}{l}\text { transposon protein, } \\
\text { putative, } \\
\text { CACTA, En/Spm sub-class }\end{array}$ \\
\hline HVUL7H17240.2 & AT4G02210.1 & Unknown & $\begin{array}{l}\text { Unknown } \\
\text { protein }\end{array}$ & LOC_Os06g39460.1 & $\begin{array}{l}\text { transposon protein, } \\
\text { putative, } \\
\text { CACTA, En/Spm sub-class, } \\
\text { expressed }\end{array}$ \\
\hline HVUL4H47192.2 & AT1G66235.1 & Unknown & $\begin{array}{l}\text { Unknown } \\
\text { protein }\end{array}$ & LOC_Os10g27370.1 & $\begin{array}{l}\text { transposon protein, } \\
\text { putative, } \\
\text { Pong sub-class, expressed }\end{array}$ \\
\hline
\end{tabular}




\begin{tabular}{|c|c|c|c|c|c|}
\hline $\begin{array}{l}\text { Hulless } \\
\text { barely_ID }\end{array}$ & Ath_ID & Gene function & Ath_Annotation & Rice_ID & Rice_Annotation \\
\hline HVUL1H37933.2 & AT3G23230.1 & $\begin{array}{l}\text { AtTDR1 } \\
\text { enhances } \\
\text { tolerance to } \\
\text { salt through } \\
\text { the } \\
\text { transcriptional } \\
\text { activation of } \\
\text { ascorbic acid } \\
\text { synthesis in } \\
\text { Arabidopsis. }\end{array}$ & $\begin{array}{l}\text { AtTDR1; } \\
\text { Integrase-type } \\
\text { DNA-binding } \\
\text { superfamily } \\
\text { protein }\end{array}$ & LOC_Os04g18650.1 & $\begin{array}{l}\text { AP2 domain containing } \\
\text { protein, } \\
\text { expressed }\end{array}$ \\
\hline HVUL4H45104.2 & AT1G71450.1 & Unknown & $\begin{array}{l}\text { Integrase-type } \\
\text { DNA-binding } \\
\text { superfamily } \\
\text { protein }\end{array}$ & LOC_Os11g13840.1 & $\begin{array}{l}\text { AP2 domain containing } \\
\text { protein, expressed }\end{array}$ \\
\hline HVUL1H36756.2 & AT1G61110.1 & Unknown & $\begin{array}{l}\text { NAC025, NAC } \\
\text { domain } \\
\text { containing } \\
\text { protein } 25\end{array}$ & LOC_Os07g48450.1 & $\begin{array}{l}\text { no apical meristem } \\
\text { protein, } \\
\text { putative, expressed }\end{array}$ \\
\hline HVUL3H56913.2 & $\mathrm{Na}$ & Unknown & $\mathrm{Na}$ & $\mathrm{Na}$ & $\mathrm{Na}$ \\
\hline HVUL3H21712.2 & AT5G63790.1 & $\begin{array}{l}\text { ANAC102 } \\
\text { appears to } \\
\text { have a role in } \\
\text { mediating } \\
\text { response to } \\
\text { low oxygen } \\
\text { stress } \\
\text { (hypoxia) in } \\
\text { germinating } \\
\text { seedlings. }\end{array}$ & $\begin{array}{l}\text { NAC102, NAC } \\
\text { domain } \\
\text { containing } \\
\text { protein } 102\end{array}$ & LOC_Os01g60020.1 & $\begin{array}{l}\text { NAC domain transcription } \\
\text { factor, } \\
\text { putative, expressed }\end{array}$ \\
\hline HVUL2H41931.2 & AT1G09340.1 & $\begin{array}{l}\text { CSP41B was } \\
\text { significantly } \\
\text { repressed } \\
\text { upon water } \\
\text { stress. } \\
\text { miR399f } \\
\text { might also } \\
\text { modulates } \\
\text { plant } \\
\text { responses to } \\
\text { salt, } \\
\text { ABA, and } \\
\text { drought,by } \\
\text { regulating the } \\
\text { expression of } \\
\text { ABF3 and } \\
\text { CSP41b. }\end{array}$ & $\begin{array}{l}\text { CSP41B, } \\
\text { chloroplast } \\
\text { RNA binding }\end{array}$ & LOC_Os12g23180.1 & $\begin{array}{l}\text { 3-beta hydroxysteroid } \\
\text { dehydrogenase/isomerase } \\
\text { family protein, putative, } \\
\text { expressed }\end{array}$ \\
\hline HVUL4H24905.2 & AT3G24310.1 & $\begin{array}{l}\text { Promoter- } \\
\text { based } \\
\text { integration in } \\
\text { plant defense } \\
\text { regulation. }\end{array}$ & $\begin{array}{l}\text { ATMYB71, } \\
\text { myb domain } \\
\text { protein } 305\end{array}$ & LOC_Os03g04900.1 & $\begin{array}{l}\text { MYB family transcription } \\
\text { factor }\end{array}$ \\
\hline
\end{tabular}

To reveal DNA methylation status of the above 15 specific DMR TFs that appear to be differentially methylated by the imposition of drought stress, the sequence corresponding to upstream of TSS, gene body, and downstream of TSS was subjected to bisulfate sequencing by using the modified version of the previous SNV-calling method. We mainly focused on the three TFs 
(HVUL6H08680.2, HVUL4 h39100.2, and HVUL2H41931.2) described above. In gene HVUL6H08680.2, the significantly differential methylation locates in the gene body, which means the cytosines were demethylated after exposure to salinity stress for $48 \mathrm{~h}$ in $\mathrm{XL}$ (Fig. 5A). In gene HVUL4 h39100.2, the significantly differential methylation exhibits in upstream of TSS, and the methylation levels in $\mathrm{XL}$ are notably lower than that in $\mathrm{DQ}$ after exposed to drought conditions for $4 \mathrm{~h}$ (Fig. 5B). In gene HVUL2H41931.2, the significantly differential methylation locates in downstream of the TSS, which means it is hypermethylated in stressed XL seedlings (Fig. S2). Clearly, DNA methylation in HVUL6H08680.2, HVUL4 h39100.2, and HVUL2H41931.2 could be affected by drought-stress.

\section{Discussion}

Reactive oxygen species (ROS) significantly accumulates in plant tissues exposed to drought conditions. We investigated changes of Malondialdehyde (MDA) contents and enzymatic activity (Catalase, Peroxidase) both in leaves and roots after exposure to drought for $48 \mathrm{~h}$ in drought-tolerant variety $\mathrm{XL}$ and sensitive one $\mathrm{DQ}$, respectively. Interestingly, similar dynamical changes was observed both in leaves and roots in XL and DQ. We only sequenced DNA methylomes of the leaves in hulless barley in this study. It is necessary to analyze and compare the DNA methylomes between leaves and roots, which could be considered as a potential method to uncover the response pathway to drought conditions.

We further determined and analyzed the $\mathrm{CG}, \mathrm{CHG}, \mathrm{CHH}$ methylation rates in $\mathrm{XL}$ and $\mathrm{DQ}$. The results revealed that there were no signifcant genome-wide changes in $\mathrm{CG}$ or $\mathrm{CHG}$ methylation rates between the two varieties, while $\mathrm{CHH}$ methylation rates did not. Then, we analyzed the number of CG-type, CHG-type and CHH-type DMR in XL and DQ at 4h. There were 1104 CG-type DMR, 660 CHG-type DMR and 76 CHH-type DMR in XL, but there were only 15 CG-type DMR, 18 CHG-type DMR and 29 CHH-type DMR in DQ. However, the CG-type DMR and CHG-type DMR sharply decline in drought-sensitive variety DQ when compared to XL, while the $\mathrm{CHH}$ type does not. It is possible that the extremely low $\mathrm{CHH}$ methylation rates result in the less $\mathrm{CHH}$-type number. $\mathrm{CHH}$ methylation is specifically perpetuated by the combined action of siRNAs and DRM2. Thus, it indicates the siRNAs and DRM2 could play important roles in response to drought stress.

In order to identify differentially methylation regions related transcription factors (TF) in hulless barley after exposure to drought stress, 1003 TFs were identified according from Tibetan hulless barley, which is homologous to these from Arabidopsis thaliana and rice(Rohit et al., 2016). Finally, 15 specific DMR related TFs were identified, which exhibit significant methylation changes under drought stimuli. The Arabidopsis homologues of 3 TFs (HVUL6H08680.2, HVUL4 h39100.2, HVUL2H41931.2) have been proved to be involved in response to drought conditions. Therefore, DNA methylation regulate responsiveness to environmental stimuli by methylating transcription factors in hulless barely.

Altogether, it is the first time that the roles of DNA methylation in drought responsiveness were revealed in Tibetan hulless barley. Significant genome-wide changes were found in $\mathrm{CHH}$ methylation rates between two contrasting varieties (XL and DQ). They showed obviously different response to drought stress both in DMR numbers and antioxidant activities. Gene ontology analysis confirm DMR related genes in XL could involve in defense response and response to stimulus. Of the $1003 \mathrm{TFs}, 26$ unique TFs appeared to be differentially methylated. Intriguingly, 15 specific DMR related TFs exhibiting special methylation changes exposed to drought stress were identified, and 7 TFs of those might involve in response to drought stress or other abiotic stresses. Finally, we found methylation levels of some transcription factors have changed significantly under drought-stress treatment such as HVUL6H08680.2, HVUL4 h39100.2, and HVUL2H41931.2 whose gene homologue from Arabidopsis thaliana involve in responses to drought stresses. Therefore, our results proved that hulless barely might respond to drought stress via methylation on transcription factors.

\section{Declarations}

\section{Acknowledgments}

This work was supported by the following funding sources:

Tibet Autonomous Region Financial Special Fund (XZ202101ZD0004N).

Technical system of barley industry(CARS-05-01A-07).

2020 Special Fund Project for the Central Government to Guide Local Science and Technology Development( XZ202001YD0027C).

Page 9/15 
Mingzhai Yu and Yuzhen Basang conceived and supervised the work. Qijun Xu performed the DNA methylation analyses. Haizhen Yang perfomed the biochemical experiments. Haizhen Yang and Wang Mu planted the hulless barley. DunZhu Jabu wrote the article with contributions from all other authors.

\section{Conflict of Interest Statement}

The authors have declared that there is no conflict of interest.

\section{References}

1. Allen GC, Flores-Vergara MA, Krasynanski S, Kumar S, Thompson WF (2006) A modified protocol for rapid DNA isolation from plant tissues using cetyltrimethylammonium bromide. Nat Protoc 1(5):2320

2. Arthur B, Qiang H, Pooja N, Liam S, Hannah G, Matthew M,... Yong-Qiang A (2018) Dynamic DNA Methylation in Plant Growth and Development. Int J Mol Sci 19(7):2144

3. Boyko A, Blevins T, Yao Y, Golubov A, Bilichak A, Inytskyy Y,.. . Kovalchuk I (2010) Transgenerational Adaptation of Arabidopsis to Stress Requires DNA Methylation and the Function of Dicer-Like Proteins. Plos One 5(4):e9514

4. Du J, Zhong X, Bernatavichute YV, Stroud H, Feng S, Caro E,.. . Tu A (2012) Dual Binding of Chromomethylase Domains to H3K9me2-Containing Nucleosomes Directs DNA Methylation in Plants. Cell 151(1):167-180

5. Du JB, Yuan S, Chen Y-E, Sun X, Zhang Z-W, Xu F,... Lin H-H (2011) Comparative expression analysis of dehydrins between two barley varieties, wild barley and Tibetan hulless barley associated with different stress resistance. Acta Physiol Plant 33(2):567574

6. Flowers TJ (1989) Effects of salinity on plant growth and crop yields. Environmental Stress in Plants Biochemical \& Physiological Mechanisms

7. Fuks FO (2005) DNA methylation and histone modifications: teaming up to silence genes. Curr Opin Genet Dev 15(5):490-495

8. Hai P, Zhang J (2009) Plant genomic DNA methylation in response to stresses: Potential applications and challenges in plant breeding. Progress in Natural Science:Materials International 19(9):1037-1045

9. Iqbal MM, Murtaza G, Saqib ZA, Ahmad R (2015) Growth and Physiological Responses of Two Rice Varieties to Applied Lead in Normal and Salt-Affected Soils. International Journal of Agriculture Biology 17(5):901-910

10. Kasai H, Kawai K (2009) DNA Methylation at the C-5 Position of Cytosine by Methyl Radicals: A Possible Role for Epigenetic Change during Carcinogenesis by Environmental Agents. Chem Res Toxicol 22(6):984-989

11. Ku JJ, Lim CW, Park YD (2006) Methylation Pattern Analysis of Double-Transformed Tobacco Plants with Antisense-Oriented MET1 Gene. Horticulture Environment Biotechnology 47:307-312

12. Lenka SK, Katiyar A, Chinnusamy V, Bansal KC (2015) Comparative analysis of drought-responsive transcriptome in Indica rice genotypes with contrasting drought tolerance. Plant Biotechnol J 9(3):315-327

13. Li H, Guo Q, Lan X, Zhou Q, Wei N (2014) Comparative expression analysis of fiveWRKYgenes from Tibetan hulless barley under various abiotic stresses between drought-resistant and sensitive genotype. Acta Physiol Plant 36(4):963-973

14. Li Q, Gent JI, Zynda G, Song J, Makarevitch I, Hirsch CD,.. . Mcginnis KM (2015) RNA-directed DNA methylation enforces boundaries between heterochromatin and euchromatin in the maize genome. Proc Natl Acad Sci U S A 112(47):14728-14733

15. Liang J, Xin C, Guangbing D, Zhifen P, Haili Z, Qiao L,.. . Maoqun Y (2017) Dehydration induced transcriptomic responses in two Tibetan hulless barley (Hordeum vulgare var. nudum) accessions distinguished by drought tolerance. Bmc Genomics 18(1):775

16. Ma L, Hatlen A, Kelly LJ, Becher H, Wang W, Kovarik A,.. . Leitch AR (2015) Angiosperms Are Unique among Land Plant Lineages in the Occurrence of Key Genes in the RNA-Directed DNA Methylation (RdDM) Pathway. Genome Biology Evolution 7(9):26482662

17. Macisaac JL, Bogutz AB, Morrissy AS, Lefebvre L (2012) Tissue-specific alternative polyadenylation at the imprinted gene Mest regulates allelic usage at Copg2. Nucleic Acids Res 40(4):1523-1535

18. Melamed-Bessudo C, Levy AA (2012) Deficiency in DNA methylation increases meiotic crossover rates in euchromatic but not in heterochromatic regions in Arabidopsis. Proc Natl Acad Sci USA 109(16):E981-E988 
19. Moa X, Liua S, Lina Z, Xub Y, Xianga Y (2005) Prediction of crop yield, water consumption and water use efficiency with a SVATcrop growth model using remotely sensed data on the North China Plain. Ecol Model 183(2):301-322

20. Rohit J, Balwant HWS, Abhishek S, B., A., D. Z., A., L. A.,.. . L., S.-P. S (2016) Transcription Factors and Plants Response to Drought Stress: Current Understanding and Future Directions. Front Plant Sci 7(e102529):1029

21. Sasaki T, Kobayashi A, Saze H, Kakutani T (2012) RNAi-independent de novo DNA methylation revealed in Arabidopsis mutants of chromatin remodeling gene DDM1. Plant J 70(5):750-758

22. Schmedes A, H?Imer G (1989) A new thiobarbituric acid (TBA) method for determining free malondialdehyde (MDA) and hydroperoxides selectively as a measure of lipid peroxidation. J Am Oil Chem Soc 66(6):813-817

23. Serre D, Lee BH, Ting AH (2009) Mbd-isolated genome sequencing provides a high-throughput and comprehensive survey of DNA methylation in the human genome. Nucleic Acids Res. Nucleic Acids Research,38,2(2009-11-11), 38(2), 391-399

24. Song F, Mahmood S, Ghosh S, Liang P, Smiraglia DJ, Nagase H, Held WA (2009) Tissue specific differentially methylated regions (TDMR): Changes in DNA methylation during development. Genomics 93(2):130-139

25. Su J, Wang Y, Xing X, Liu J, Yong Z (2014) Genome-wide analysis of DNA methylation in bovine placentas. Bmc Genomics 15(1):12

26. Sultana R, Khurram B, Akihiro M, Maho T, Motoaki S (2016) Transcriptomic Analysis of Soil-Grown Arabidopsis thaliana Roots and Shoots in Response to a Drought Stress. Front Plant Sci 7(180):180

27. Tamas L, Mistrik I, Zelinova V (2016) Cadmium activates both diphenyleneiodonium- and rotenone-sensitive superoxide production in barley root tips. Planta 244(6):1277-1287. doi:10.1007/s00425-016-2587-2

28. Uthup TK, Ravindran M, Bini K, Thakurdas S (2011) Divergent DNA Methylation Patterns Associated with Abiotic Stress in Hevea brasiliensis. Mol Plant 4(6):996-1013

29. Wang W, Qiao Q, Fan S, Yinxiao W, Dandan X, Zhikang L, Binying F (2016) Genome-Wide Differences in DNA Methylation Changes in Two Contrasting Rice Genotypes in Response to Drought Conditions. Front Plant Sci 7:507

30. Xi Y, Li W (2009) BSMAP: whole genome bisulfite sequence MAPping program. Bmc Bioinformatics 10(1):232

31. Xu QJ, Wang YL, Wei ZX, Yuan HJ, Zeng XQ, Tashi N (2016) Cloning and functional characterization of the HbSYR1 gene encoding a syntaxin-related protein in Tibetan hulless barley (Hordeum vulgare L. var. nudum HK. f.). Genetics \& Molecular Research, 16(3)

32. Yu C, Lv C, Shi Y (2009) The Effect of Steviol Glycosides Blending Liquid on Senescence after Flowering in Upland Rice. Journal of Agronomy 8(3):113-116

33. Zhang X, Lu G, Long W, Zou X, Li F, Nishio T (2014) Recent progress in drought and salt tolerance studies in Brassica crops. Breed Sci 64(1):60-73

34. Zhang X, Yazaki J, Sundaresan A, Cokus S, Chan SW-L, Chen H,.. Jacobsen SE (2006) Genome-wide High-Resolution Mapping and Functional Analysis of DNA Methylation in Arabidopsis. Cell 126(6):1189

35. Zhou HR, Zhang FF, Ma ZY, Huang HW, Jiang L, Cai T,.. . He XJ (2013) Folate polyglutamylation is involved in chromatin silencing by maintaining global DNA methylation and histone H3K9 dimethylation in Arabidopsis. Plant Cell 25(7):2545-2559

36. Zong W, Zhong X, You J, Xiong L (2013) Genome-wide profiling of histone H3K4-tri-methylation and gene expression in rice under drought stress. Plant Mol Biol 81(1-2):175-188

37. Zubko E, Gentry M, Kunova A, Meyer P (2012) De novo DNA methylation activity of methyltransferase 1 (MET1) partially restores body methylation in Arabidopsis thaliana. Plant Journal for Cell Molecular Biology 71(6):1029-1037

\section{Figures}


A

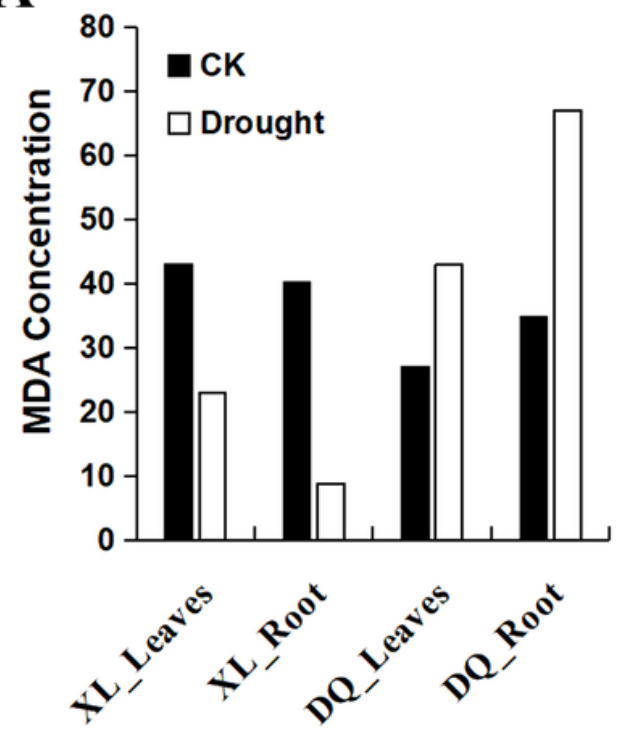

B

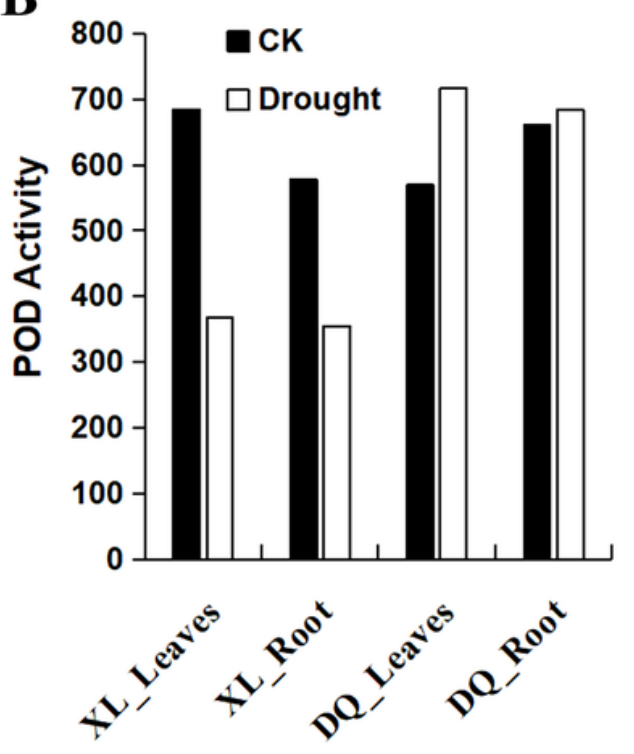

C
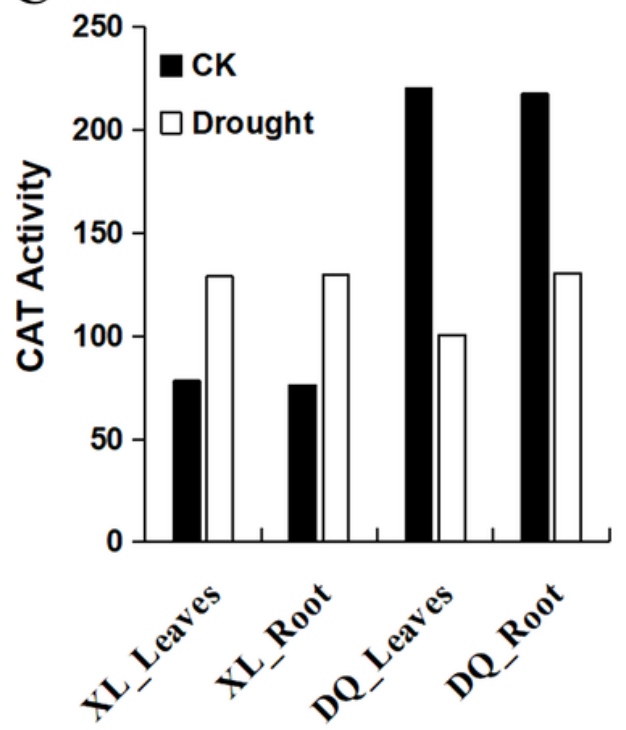

Figure 1

The physiological change in two contrasting hulless barely varieties. MDA, malondialdehyde; POD, peroxidase; CAT, catalase; $\mathrm{XL}$, the drought-tolerant hulless barely; DQ, the drought-sensitive hulless barely; Drought, the hulless barely varieties were treated with $21 \%$ polyethylene glycol (PEG) 6000 solutions to achieve an osmotic potential; CK, the hulless barely grew in normal conditions.

A

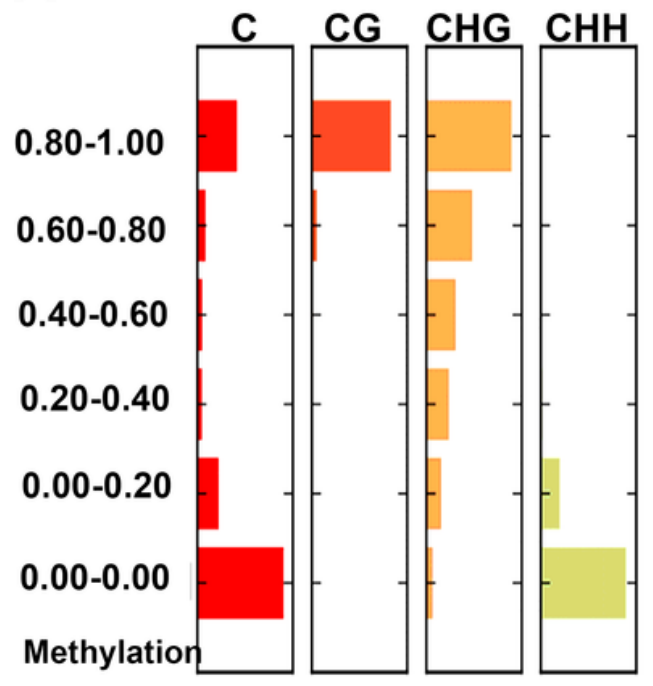

Level
B

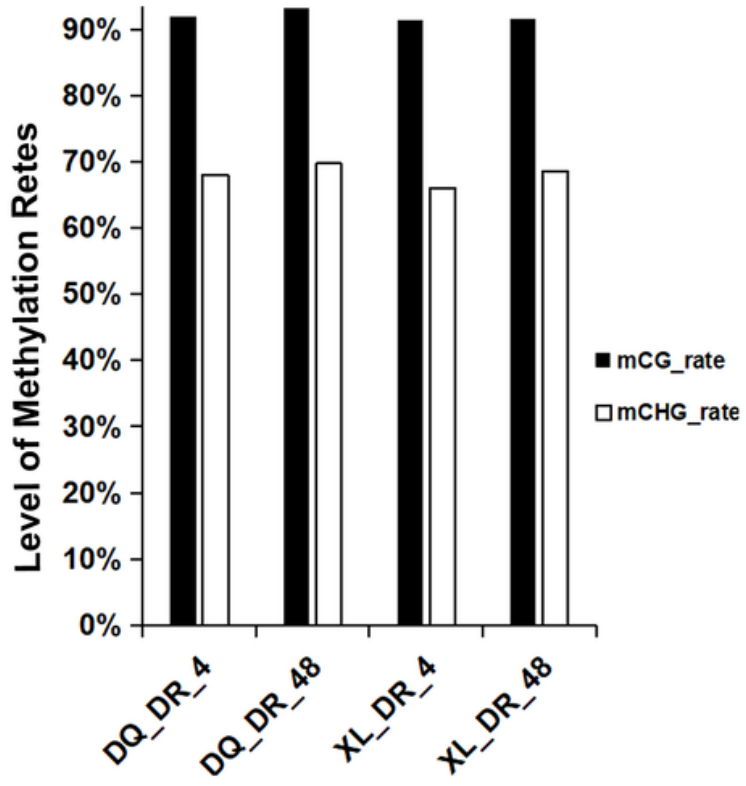

C

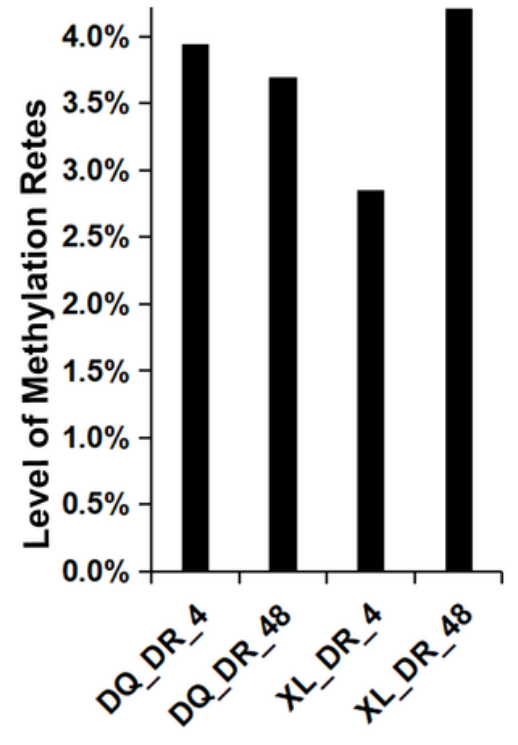

Figure 2

The methylation rates between the drought-tolerant variety $(\mathrm{XL})$ and the drought-sensitive one (DQ). (A). Methylation levels in CG, $\mathrm{CHG}$, and $\mathrm{CHH}$ contents; (B). The $\mathrm{CG}$ and $\mathrm{CHG}$ methylation rates; (C). The $\mathrm{CHH}$ methylation rates. 
A

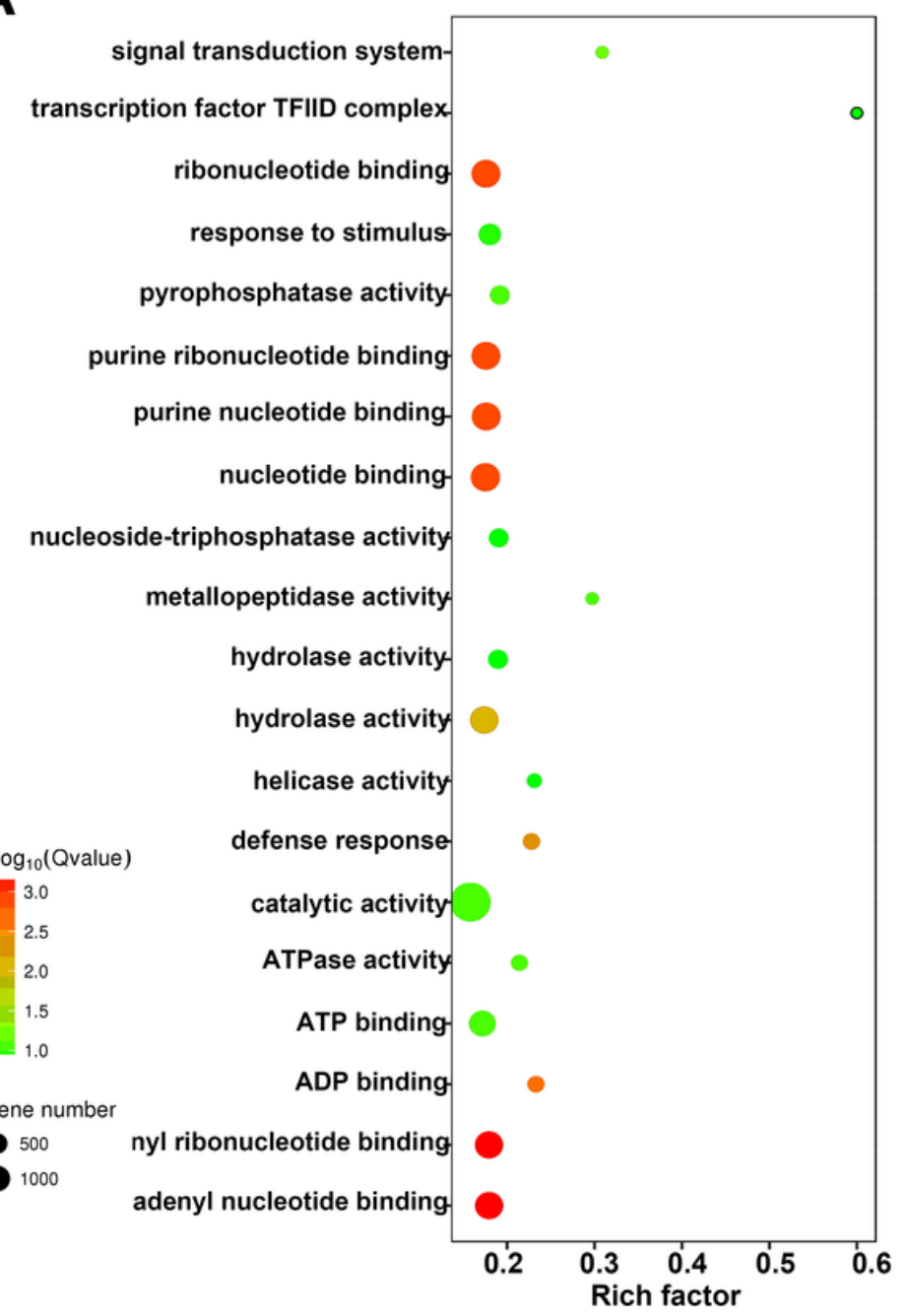

B

threonine-type peptidase activity

threonine-type endopeptidase activity

ribonucleotide binding

response to DNA damage stimulus

purine ribonucleotide binding

purine nucleotide binding

protein refolding

nucleotide binding

nucleoside-triphosphatase activity

DNA repair

DNA metabolic process

cellular response to stress

cellular response to stimulus

carbohydrate biosynthetic process $-\log _{10}$ (Qvalue)

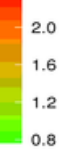

2.0

1.6

0.8

Gene number

- 400

800

1600 catalytic activity.

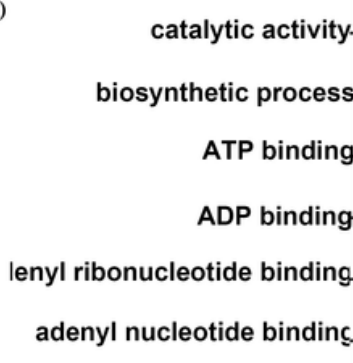

adenyl nucleotide bindinc

Figure 3

Gene ontology analysis of CG-type related DMR genes within XL in category of DR_48_vs_DR_4(A); gene ontology analysis by CGtype related $\mathrm{DMR}$ genes between $\mathrm{XL}$ and $\mathrm{DQ}$ exposed to drought stress.

A

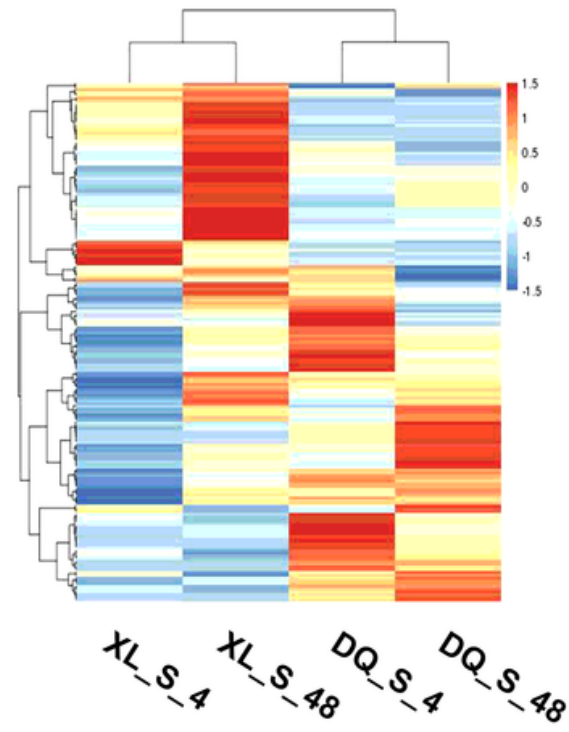

B

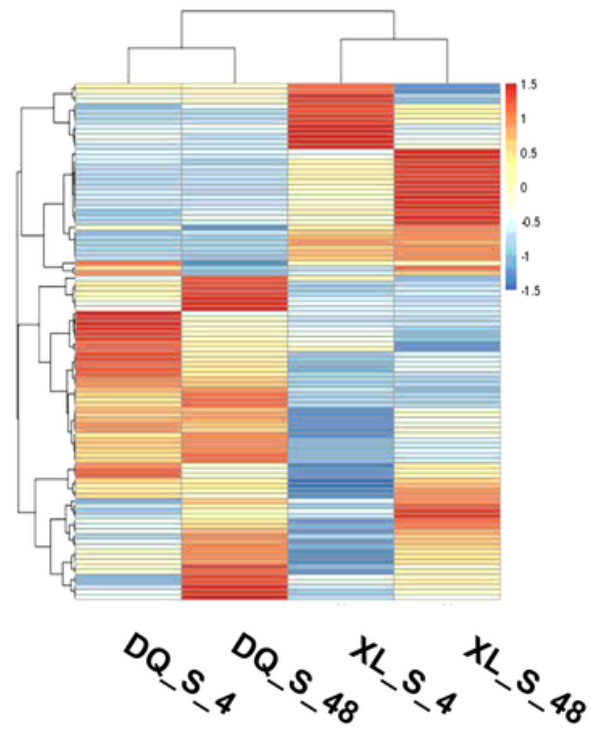

C

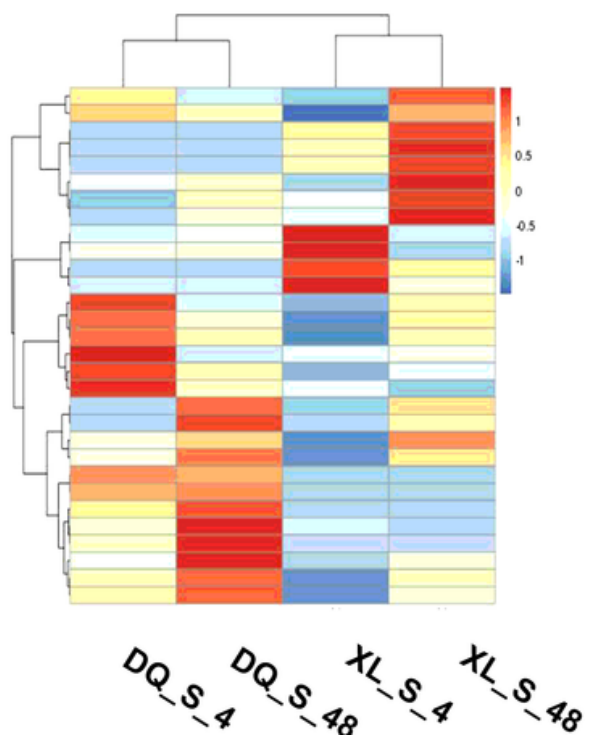

Figure 4 
The expression profiles of CG-type (A), CHG-type (B) and CHH-type (C) related genes between drought-tolerant varieties XL and drought-sensitive one DQ. XL:drought-tolerant variety hulless barely; DQ: the drought-sensitive hulless barely; CK: hulless barely were exposed to normal conditions; S: hulless barely were exposed to drought conditions.

A

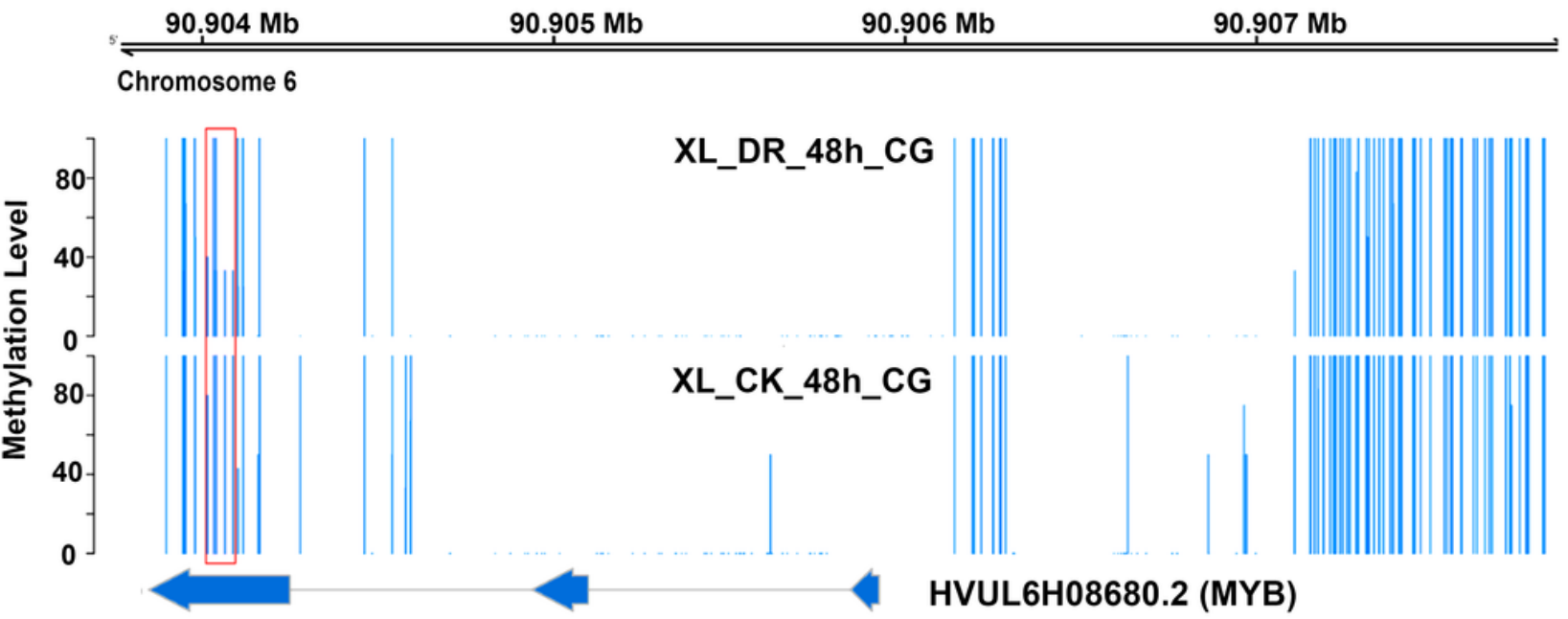

\section{B}

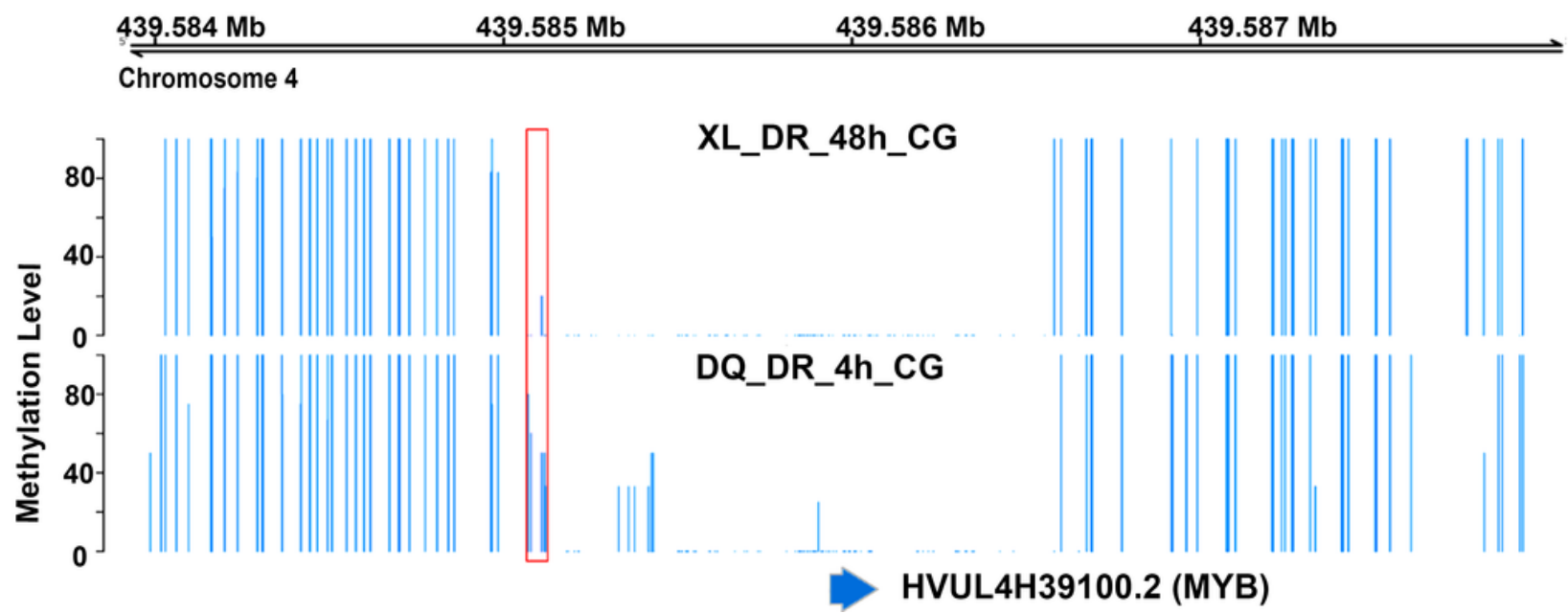

Figure 5

Methylation status of the specific DMR transcription factors. (A) Methylation status of HVUL6H08680.2; (B). Methylation status of HVUL4 h39100.2; XL:drought-tolerant variety hulless barely; DQ: the drought-sensitive hulless barely; CK: hulless barely were exposed to normal conditions; DR: hulless barely were exposed to drought conditions.

\section{Supplementary Files}

This is a list of supplementary files associated with this preprint. Click to download.

- Fig.S1.png

- Fig.S2.png

- SupplementaryFigureLegend.docx

- Tables1.xls

- Tables2.xls

- Tables3.xls

- Tables4.xls

- Tables5.xls 
- Tables6.xls

Page 15/15 